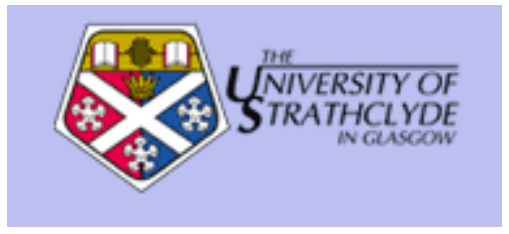

Heath, M.R. and Astthorsson, O.S. and Dunn, J. and Ellertsen, B. and Gaard, E. and Gislason, A. and Gurney, W.S.C. and Hind, A.T. and Irigoien, X. and Melle, W. and Niehoff, B. and Olsen, K. and Skreslet, S. and Tande, K.S. (2004) Comparative analysis of Calanus finmarchicus demography at locations around the Northeast Atlantic. ICES Journal of Marine Science, 61 (4). pp. 698-708. ISSN 1054-3139

http://strathprints.strath.ac.uk/18579/

This is an author produced version of a paper published in ICES Journal of Marine Science, 61 (4). pp. 698-708. ISSN 1054-3139. This version has been peer-reviewed but does not include the final publisher proof corrections, published layout or pagination.

Strathprints is designed to allow users to access the research output of the University of Strathclyde. Copyright (C) and Moral Rights for the papers on this site are retained by the individual authors and/or other copyright owners. You may not engage in further distribution of the material for any profitmaking activities or any commercial gain. You may freely distribute both the url (http://strathprints.strath.ac.uk) and the content of this paper for research or study, educational, or not-for-profit purposes without prior permission or charge. You may freely distribute the url (http://strathprints.strath.ac.uk) of the Strathprints website.

Any correspondence concerning this service should be sent to The Strathprints Administrator: eprints@cis.strath.ac.uk 


\title{
Comparative analysis of Calanus finmarchicus demography at locations around the Northeast Atlantic
}

\author{
M. R. Heath, O. S. Astthorsson, J. Dunn, B. Ellertsen, \\ E. Gaard, A. Gislason, W. S. C. Gurney, A. T. Hind, \\ X. Irigoien, W. Melle, B. Niehoff, K. Olsen, S. Skreslet, \\ and K. S. Tande
}

Heath, M. R., Astthorsson, O. S., Dunn, J., Ellertsen, B., Gaard, E., Gislason, A., Gurney, W. S. C., Hind, A. T., Irigoien, X., Melle, W., Niehoff, B., Olsen, K., Skreslet, S., and Tande, K. S. 2000. Comparative analysis of Calanus finmarchicus demography at locations around the Northeast Atlantic.

\begin{abstract}
Standardized time-series sampling was carried out throughout 1997 at seven locations around the Northeast Atlantic to investigate regional variations in the seasonal demography of Calanus finmarchicus. Sites ranged from an inshore location in the North Sea, where $C$. finmarchicus formed only a small component of the zooplankton ( $<10 \mathrm{mgC} \mathrm{m}{ }^{-2}$ during spring and early summer), to the shelf south of Iceland, and Weathership M in the Norwegian Sea, where the species dominated the zooplankton (>2000 $\mathrm{mgC} \mathrm{m} \mathrm{m}^{-2}$ during spring and summer). The internal consistency of the demographic time series from each site was investigated by three partial models of life-cycle processes. In general, the demography of late copepodites could be accounted for by a relatively simple forecast model of stage development and diapause. However, there was a large discrepancy between nowcast estimates of egg production based on female abundance, temperature, and chlorophyll, and hindcast simulations of the egg production required to account for the observed abundance of early copepodite stages. The results point to a gap in our understanding of seasonal variations in rates of egg production and/or survival of nauplii. Overall, the population sampled at Weathership $\mathrm{M}$ appeared to be reasonably self-contained, but all other sites were reliant on invasion of overwintered stock in spring. At least two generations were observed at all but one site, but the extent to which these were generated by discrete bursts of egg production varied between sites and seemed to be partly dependent on the proximity to an overwintering location.
\end{abstract}

Key words: Atlantic, egg production, modelling stage development, time-series sampling, zooplankton.

M. R. Heath and J. Dunn: Marine Laboratory, PO Box 101, Victoria Road, Aberdeen AB11 9DB, Scotland, UK [tel: +44 1224876 544; fax: +44 1224295 511; e-mail: heathmr@marlab.ac.uk].O.S. Astthorsson and A. Gislason: Marine Research Institute, Skúlagata 4, Box 1390, 121 Reykjavik, Iceland. B. Ellertsen and W. Melle: Institute of Marine Research, PO Box 1870 Nordnes 5817, Bergen, Norway. E. Gaard: Fisheries Laboratory of the Faroes, Noatun, Box 3051, FO-110 Tórshavn, Faroe Islands. W. S. C. Gurney and A. T. Hind: Department of Statistics and Modelling Science, University of Strathclyde, 26 Richmond Street, Glasgow G1 1XH, Scotland, UK. X. Irigoien: formerly Plymouth Marine Laboratory, now George Deacon Division, Southampton Oceanography Centre, Empress Dock, Southampton SO14 3ZH, England, UK. B. Niehoff: Alfred Wegener Institute, Columbusstrasse 1, 27568 Bremerhaven, Germany. K. Olsen and S. Skreslet: Nordland College, Faculty of Fisheries and Natural Science, 8049 Bodo, Norway. K. S. Tande: University of Tromsø, Norwegian College of Fishery Science, 9037 Tromsø, Norway. 


\section{Introduction}

The boreal copepod Calanus finmarchicus is widely distributed in the North Atlantic Ocean, where it is usually by far the most abundant zooplankton species (Marshall and Orr, 1957; Matthews, 1969; Conover, 1988; Longhurst and Williams, 1992). At the northern limits of its distribution, e.g. north of Iceland, it occurs along with the Arctic species $C$. glacialis and C. hyperboreus, while in the northeastern North Atlantic, in the North Sea, and in the southern part of the Norwegian Sea it co-occurs with the southern form $C$. helgolandicus (Conover, 1988). Based on CPR data, the distribution area of $C$. finmarchicus may be divided into three large subareas, each with its characteristic pattern of seasonal development in surface waters (Planque et al., 1997). These are south of Newfoundland, south of Greenland, and the northern and northeastern North Atlantic, including the Norwegian Sea. In the Northeastern Atlantic its abundance is generally low during winter (November-February), increases in March to a maximum in May/June, and returns to low winter values by September-November (Planque et al., 1997).

Although the seasonal pattern of $C$. finmarchicus biomass is generally similar on a large scale, available information indicates that on a smaller spatial scale the seasonal demography may vary considerably. Therefore the duration of the life cycle (and the number of generations that $C$. finmarchicus is able to produce in a year) has traditionally been considered to be a function of latitude (i.e. temperature). In the southern parts of its distribution range (e.g. in the Iceland Basin or North Sea), C. finmarchicus may complete two or even three generations per year (Gislason and Astthorsson, 1996; Irigoien, 1999), whereas in the northern parts (north of Iceland, northern Norway) it may achieve only one generation (Tande, 1982; Falkenhaug et al., 1997; Gislason and Astthorsson, 1998). This may depend on a number of factors, the most important probably being temperature and/or feeding conditions during reproduction and cohort development. The traditional interpretation of one generation of $C$. finmarchicus at the northern limits of the distribution area and two or even three in the southern parts has recently been disputed by Irigoien (1999), who presents results from weather station India $\left(59^{\circ} \mathrm{N}, 19^{\circ} \mathrm{W}\right)$, which indicate that interannual variations in local conditions, temperature, and phytoplankton may alter the number of generations that $C$. finmarchicus is able to produce per year.

There are few time series available that describe the full annual cycle of $C$. finmarchicus with temporal resolution in sampling of less than a month. Because of this, important events in the life history of the animals may have gone undetected. The Comparative Time-Series Sampling Programme in TASC sought to remedy this by increasing the frequency of sampling and by conducting parallel programmes at a number of disparate sites throughout 1997. Comparing those data, and diagnosing the demography, is a formidable task, and to aid the process we have applied a number of models designed to highlight internal consistency within each time series, to test our hypotheses regarding the life-cycle dynamics and indicate the key features of the demography.

\section{Material and methods}

\section{Field sampling}

A coordinated programme of sampling was carried out at seven locations covering a latitudinal range from $57^{\circ} \mathrm{N}$ to $67^{\circ} \mathrm{N}$ during 1997 and extending into 1998 (Table 1, Fig. 1). The sampling interval varied between 1 and $14 \mathrm{~d}$, depending on time of year and location, but averaged $12.5 \mathrm{~d}$ over all sites. At one site (Saltenfjorden), sampling did not commence until 1 April 1997, but continued until 20 April 1998. The 1998 data were therefore folded back into the beginning of the 1997 time series to obtain an annual series comparable with the other sites.

At each site, zooplankton were sampled with 180 $200 \mu \mathrm{m}$ mesh netting fitted to $0.07 \mathrm{~m}^{2}$ (30 cm diameter) or $0.25 \mathrm{~m}^{2}$ (56 cm diameter) mouth area WP2 nets, Bongo nets or opening and closing multinets (Table 1). A mesh aperture of $200 \mu \mathrm{m}$ retains $>95 \%$ of Calanus finmarchicus copepodite stage CI and $100 \%$ of CII and later stages, but retains only a small proportion of naupliar stages (Nichols and Thompson, 1991). The nets were towed vertically from around $10 \mathrm{~m}$ above the sea-bed to the surface at a speed of $30-40 \mathrm{~m} \mathrm{~min}^{-1}$, except at Weathership M, where sampling was confined to the upper $1600 \mathrm{~m}$. The zooplankton samples were preserved in $4 \%$ neutralized formalin until later analysis in the laboratory ashore. Subsamples of at least 200 Calanus spp. specimens were sorted from aliquots of the preserved samples and identified to copepodite moult stage (CI-CV, and sex for CVI). At five sites, $C$. finmarchicus co-occurred with $C$. helgolandicus, and in those cases the two species were discriminated for stages $\mathrm{CV}$ and CVI, but could not be routinely distinguished for CI-CIV. CV and female CVI C. finmarchicus were distinguished from $C$. helgolandicus by microscopic examination of the head shape and the curvature of the inner edge of the basal segment of the 5th leg. Male CVI of the two species were discriminated on the basis of the relative lengths of the endopod and exopod of the 5th leg. In samples that contained a mixture of C. finmarchicus and C. helgolandicus as CV-CVI, the abundances of CI-CIV were apportioned between the two species according to the ratio in the older stages. $C$. glacialis was present but scarce in samples from one site (Weathership $\mathrm{M})$, and this was treated in the same way as for $C$. helgolandicus, discrimination from $C$. finmarchicus being 
Calanus finmarchicus demography in the NE Atlantic

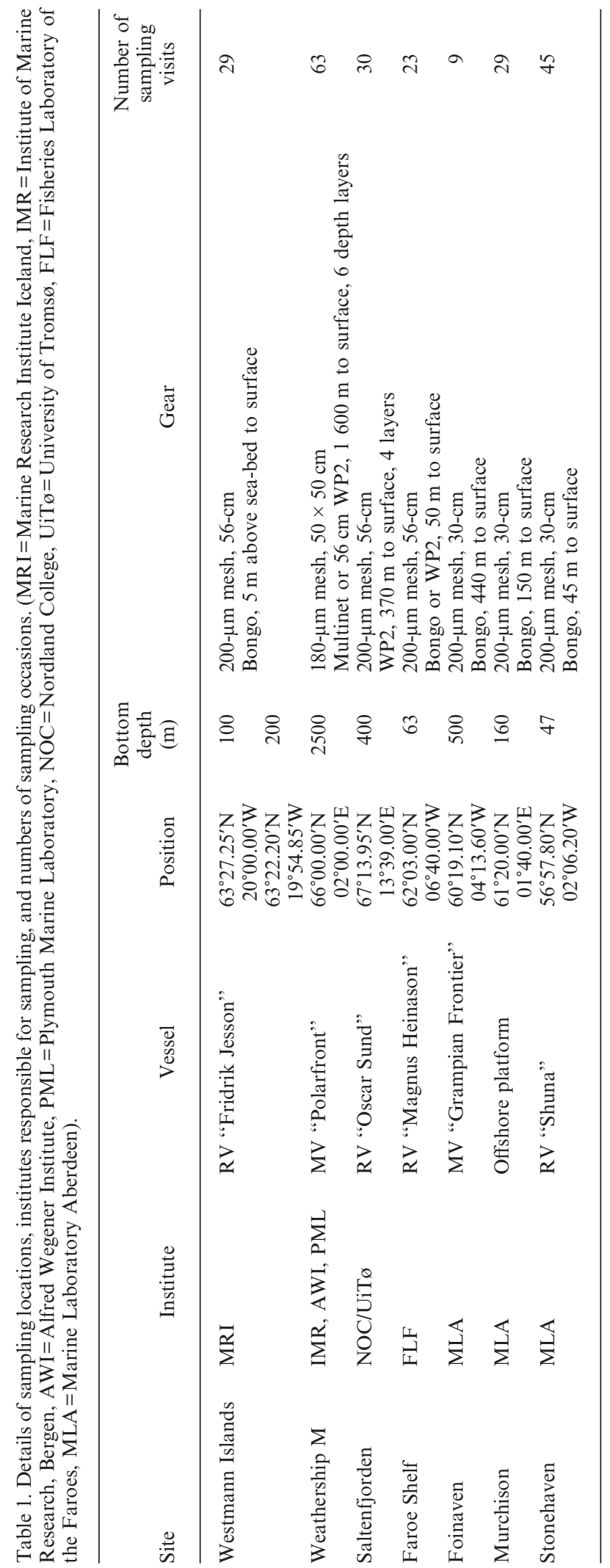




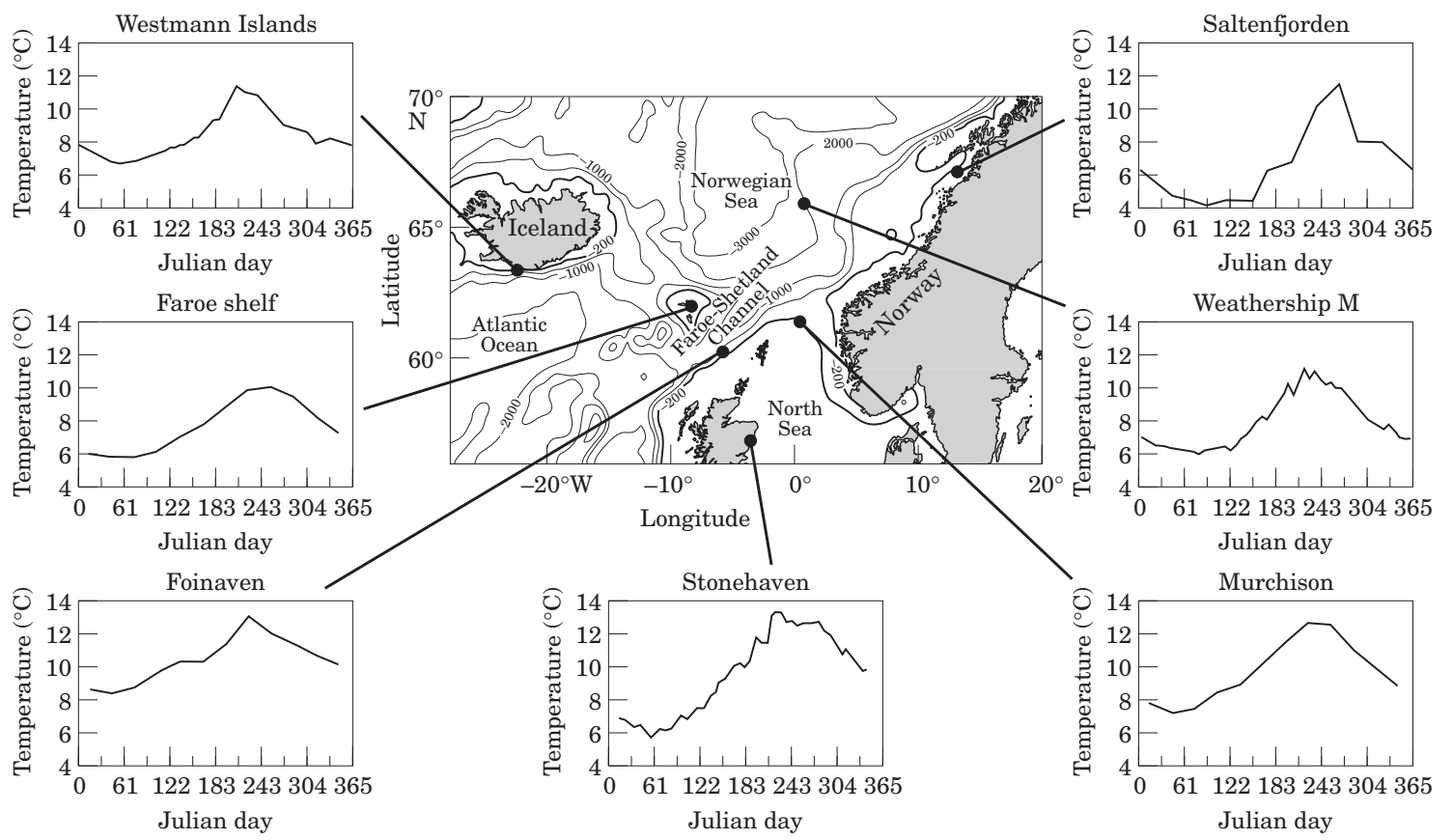

Figure 1. Locations of study sites and seasonal cycles of mean temperature in the upper $100 \mathrm{~m}$ (or surface to sea-bed where shallower).

on the basis of carapace length according to Hirche (1991). The numbers of copepodite stages in each sample were transformed to abundance $\left(\mathrm{m}^{-2}\right)$ by reference to the volume filtered during each haul. At the two sites where depth-stratified sampling was carried out (Weathership $M$ and Saltenfjorden), the abundances were calculated for the upper $100 \mathrm{~m}$ and for the whole sampled water column. Copepodite stage abundances were converted to population carbon biomass by reference to mean values of carbon content per stage (Table 2).

Water samples for analysis of chlorophyll $a$ were collected at the same date and location as the zooplankton samples. At the Westmann Islands, Faroe, and Weathership M, samples were collected at 10-m intervals between the surface and $50 \mathrm{~m}$ with water bottles. At Stonehaven, where the water column was well mixed

Table 2. Mean carbon weights of copepodite stages used to convert stage abundances to biomass. Values assembled from data present by Hay et al. (1991) and Ingvarsdóttir (1998).

Copepodite stage $\quad \mu \mathrm{gC}$ individual $^{-1}$

\begin{tabular}{lc}
\hline CI & 4.9 \\
CII & 10.3 \\
CIII & 24.6 \\
CIV & 46.8 \\
CV & 116.9 \\
CVI & 140.2 \\
\hline
\end{tabular}

throughout the year, samples were collected at a depth of $5 \mathrm{~m}$ only. At Saltenfjorden, a single integrated sample from the upper $40 \mathrm{~m}$ was collected with a hose sampler. In each case, the samples were filtered onto either GF/C or GF/F glass fibre filters, pigments extracted in acetone, and analysed spectrophotometrically. Data from samples collected in the upper $50 \mathrm{~m}$ were averaged on each occasion. At two locations (Murchison Platform in the northern North Sea and the Foinaven site west of Shetland), it was not possible to collect water samples owing to the logistics of the programme. For those sites, long-term monthly average chlorophyll concentrations were calculated from archive data held at the Marine Laboratory, Aberdeen. The data used were from samples collected in the upper $50 \mathrm{~m}$ of the water column within a $60 \mathrm{~km}$ radius of each site between 1960 and 1998. A set of month-specific deviations from these long-term mean values was then applied for 1997 and 1998. The deviations were based on widespread sampling throughout the northern North Sea in 1997 and 1998 and hence reflected regional year-specific differences in the timing and abundance of phytoplankton abundance.

Vertical profiles of salinity and temperature were obtained on each sampling date with a CTD or water bottles and reversing thermometers. The data were averaged over the upper $50 \mathrm{~m}$ for each sampling occasion. Only limited hydrographic data were obtained at three sites (Murchison Platform in the northern North Sea, 
the Foinaven site west of Shetland, and the Faroe Islands). As in the case of chlorophyll data, temperature time series for those sites were constructed by reference to long-term archive data. Monthly deviations from the long-term mean temperature were then derived by reference to the limited data collected during the programme, and to regional temperature anomalies from more widespread sampling.

\section{Models}

Three different models were applied to investigate different aspects of the time-series data from each site. The first model was designed to forecast the timing and abundances of copepodite stages CVI, CV, and CVI from the observations of CI, CII, and CIII. The second model hindcast the timing and abundance of the eggs that must have produced the observed abundances of stages CI, CII, and CIII. Both models used temperaturedependent rates of stage development. Some additional rules involving chlorophyll concentrations were incorporated into the forecast model to represent factors triggering the onset of the resting state in CIV and CV. Finally, an egg production model was applied to nowcast the changes in daily population egg production over the year, from concurrent data on temperature, chlorophyll, and female abundance. Those results were compared with the results from the hindcast model to investigate the internal consistency of the data and models.

\section{Hindcast and forecast models}

The forecast and hindcast models were based on the cohort model of Hind and Gurney (1998) and Hind et al. (2000). The model represents the development and changes in abundance of a group of identical copepods having the same birthdate and experiencing the same conditions of temperature and food. Stage development was represented by the continuous variable, c, whose value started at zero for newly spawned eggs and increased by 1 with each naupliar (NI-NVI) and copepodite (CI-CVI) moult stage to a maximum of 13 . The rate of change of $\mathrm{c}$ with time was described by a sequence of stage-specific temperature-dependent rates of development $\left(\right.$ day $\left.^{-1}\right)$, as derived from the data of Tande (1988) and Campbell (pers. comm.) by Hind et al. (2000). The model equations and parameters are given in the Appendix.

For CIV, CV, and CVI, two modes of development were invoked to represent either active growth and development to adult, or suppressed development representing diapause. Development in the suppressed state proceeded as a fixed fraction of the temperaturedependent rate at $5^{\circ} \mathrm{C}$, with a $\mathrm{Q}_{10}$ relationship describing the effects of temperature on development during diapause. Entry to the suppressed development mode was triggered by encountering food concentration below a given threshold $\left(\mathrm{F}_{\mathrm{G}}\right)$ at any time between two development points $\left(\mathrm{c}_{\mathrm{t} 1}\right.$ and $\left.\mathrm{c}_{\mathrm{t} 2}\right)$ that were located between the start of CIV and the end of CV $\left(10.0 \# \mathrm{c}_{\mathrm{e} 1}<\mathrm{c}_{\mathrm{e} 2}<12.0\right)$. An option in the model allowed for diapause copepodites to experience a different (lower) water temperature than that in the upper $100 \mathrm{~m}$. This facility was enacted at sites where hydrographic data indicated the presence of thermal stratification and where diapause copepodites were distributed in the deep.

Rate of development in diapause and sensitivity to temperature were parameterized from data presented by Ingvarsdóttir (1998) and Ingvarsdóttir et al. (1999), who measured the difference in respiration rate between diapause and non-diapause stage CV copepodites at the same temperature, and the effects of temperature on respiration in diapause animals. These data indicated that metabolism was reduced by a factor of approximately 11 in diapause animals at $5^{\circ} \mathrm{C}$, and that diapause respiration responded with a $\mathrm{Q}_{10}$ of 2.1 over the range $0-7^{\circ} \mathrm{C}$.

The abundance of copepods in a cohort was simulated by assuming constant instantaneous daily mortality rates, and extrapolating the observed abundances of $\mathrm{CI}$, CII, and CIII upwards in the case of the hindcast, and downwards in the case of forecasts. Different rates of mortality were assumed for eggs and nauplii, and for copepodites. A mortality penalty was imposed on diapause stages at temperatures $>4^{\circ} \mathrm{C}$, and a mortality benefit at $<4^{\circ} \mathrm{C}$, to represent the reduced predation rate on overwintering animals in cold water.

For each study site, the observed abundances $\left(\mathrm{m}^{-2}\right)$ of copepodite stages CI, CII, and CIII, and the temperature and chlorophyll concentrations, were first interpolated lineally to daily resolution. Each daily incidence of CI, CII, or CIII was then treated as a separate cohort, and the hindcast or forecast models applied to each cohort in turn, with a time step of $1 \mathrm{~h}$ until the cohort attained the state of either the maximum lifespan of CVI (forecast model) or newly spawned eggs. Cohorts which extended forwards into 1998 (forecast model) or backwards into 1996 (hindcast model) were "wrapped around" to the opposite end of the year and reintroduced in the appropriate month of 1997. The cohorts were assumed to begin in mid-stage $(\mathrm{c}=7.5,8.5$, and 9.5 for CI, CII, and CIII, respectively), and the initial abundances were taken as the (interpolated) observed daily abundance at stage divided by the residence time in stage on that day, to take account of multiple representation of copepodites from the same cohort in successive days of observed data. Stage residence time was estimated from the stage duration and the mortality rate (z; residence time $=$ stage duration $\times \mathrm{e}^{-\mathrm{z}}$ ). Simultaneous daily predictions of target stage abundance (eggs in the hindcast model, stages CIV, CV, and CVI in the forecast model) from different cohorts originating at the same 
source stage (CI, CII, or CIII) were then integrated. By this means, each of the three source stages provided independent estimates of daily target stage abundance, which were then averaged. Finally, the resulting daily resolution hindcasts or forecasts of target stage abundances were averaged over successive 14-d intervals through the year, corresponding to the typical sampling resolution of the original observations. Field observations of target stage abundances for comparison with the model results were also averaged over 14-d intervals.

In use, the forecast model was applied to the CI-CIII abundance data from each site, with a simple optimization of the mortality rate applied to active state CI-CV. The mortality rate was adjusted within limits to minimize the sum of the root-mean-squared residuals of the forecast abundances of each of the target stages CIV, $\mathrm{CV}$, and CVI, from the observed values. Similarly, the hindcast model was applied to the CI-CIII abundance data from each site, allowing only the mortality rate of eggs and nauplii to be adjusted within limits, to equilibrate the annual mean egg abundance with that estimated from the nowcast model (see below). Mortality rate of CI-CIII was fixed at $0.005 \mathrm{~d}^{-1}$ for the hindcast model runs, corresponding to the typical results of the forecast model.

\section{Egg production nowcast model}

Daily rate of population egg production was estimated from the observed time series of female abundance, chlorophyll, and temperature, after interpolation to daily resolution. Egg production was then converted to estimated egg abundance by multiplying by the egg stage residence time.

Hind et al. (2000) derived a relationship between rate of egg production (adult ${ }^{-1} \mathrm{~d}^{-1}$ ) and chlorophyll concentration from data presented by Hirche et al. (1998). However, this was a simplified relationship that ignored temperature dependency and did not recognize any threshold chlorophyll concentration for the onset of egg production. Various authors have suggested that the onset of egg production requires a chlorophyll concentration of between 0.2 and $2 \mathrm{mg} \mathrm{m}^{-3}$ (8-80 $\mathrm{mgC} \mathrm{m}^{-3}$, assuming carbon:chlorophyll=40). Laboratory experiments in which Calanus have been fed unialgal cultures usually indicate a high threshold $\left(>60 \mathrm{mgC} \mathrm{m}^{-3}\right.$; e.g. Runge, 1985), but the majority of field observations suggest a considerably lower threshold ( $<20 \mathrm{mgC} \mathrm{m}^{-3}$; e.g., Richardson et al., 1999). In part, the field results may reflect the fact that Calanus is not exclusively herbivorous. Based on the data of Richardson et al. (1999), a food threshold of $0.2 \mathrm{mg}$ chlorophyll $\mathrm{m}^{-3}$ $\left(8 \mathrm{mgC} \mathrm{m}^{-3}\right)$ was incorporated into the functional relationship of Hind et al. (2000), and the model refitted to the data presented by Hirche et al. (1998).

In terms of temperature dependency of egg production, data from Hirche et al. (1998) indicate a high $\mathrm{Q}_{10}$ value for egg production of between 4 and 5 for temperatures in the range $0-8^{\circ} \mathrm{C}$. There are also laboratory data which indicate that egg production is still possible at temperatures as high as $15^{\circ} \mathrm{C}$, even though the species is rarely found in the sea at temperatures in excess of $12-13^{\circ} \mathrm{C}$ (e.g. Runge, 1985). Unfortunately, it is difficult to merge all available laboratory information into a coherent data set to assess the temperature response over the full tolerance range.

An additional complication is that there appears to be a seasonal component to the rate of egg production of females. Hirche et al. (1998) noted that females collected during summer, which may have been first or second generation, produced markedly fewer eggs $(<25 \%)$ under equivalent experimental conditions than females collected in spring, which were probably survivors of the overwintering stock. They suggested that endogenous factors may be involved. Alternatively, the composition of natural food consumed prior to the experimental incubations of summer-caught copepods may have inhibited egg production. Similarly, Niehoff et al. (1999) found that egg production per female during the days following the 1997 spring phytoplankton bloom at Weathership $M$ was substantially less than would have been expected on the basis of laboratory-based relationships with temperature and algal biomass. To summarize both the seasonal effect and the poorly quantified upper temperature limit for egg production, temperature dependency was represented in the nowcast model by a parabolic function which approximated to a $\mathrm{Q}_{10}$ response fitted to the data of Hirche et al. (1998) between 4 and $6^{\circ} \mathrm{C}$, but decreased rather than increased at higher temperatures, approaching zero at $13^{\circ} \mathrm{C}$ (Appendix and Table 6). The performances of the $\mathrm{Q}_{10}$ and parabolic response functions were evaluated by simulating the 1997 time series of rate of egg production at Weathership M from observed temperature and chlorophyll data, and comparing the results from both models with the data presented by Niehoff et al. (1999).

In use, the nowcast model was applied to the observed female CVI abundance, temperature and chlorophyll data from each site, with no site-specific adjustment of parameters. A fixed rate of egg mortality of $0.1 \mathrm{~d}^{-1}$ was applied to estimate the stage residence time, the results being relatively insensitive to variations in this parameter compared to variations in stage duration as a result of the seasonal variations in temperature.

\section{Results}

\section{Temperature and chlorophyll}

Annual mean temperature (Table 3) was highest at the Foinaven site located on the continental slope directly in the path of the warm Atlantic inflow to the Norwegian Sea through the Faroe-Shetland Channel. 
Calanus finmarchicus demography in the NE Atlantic

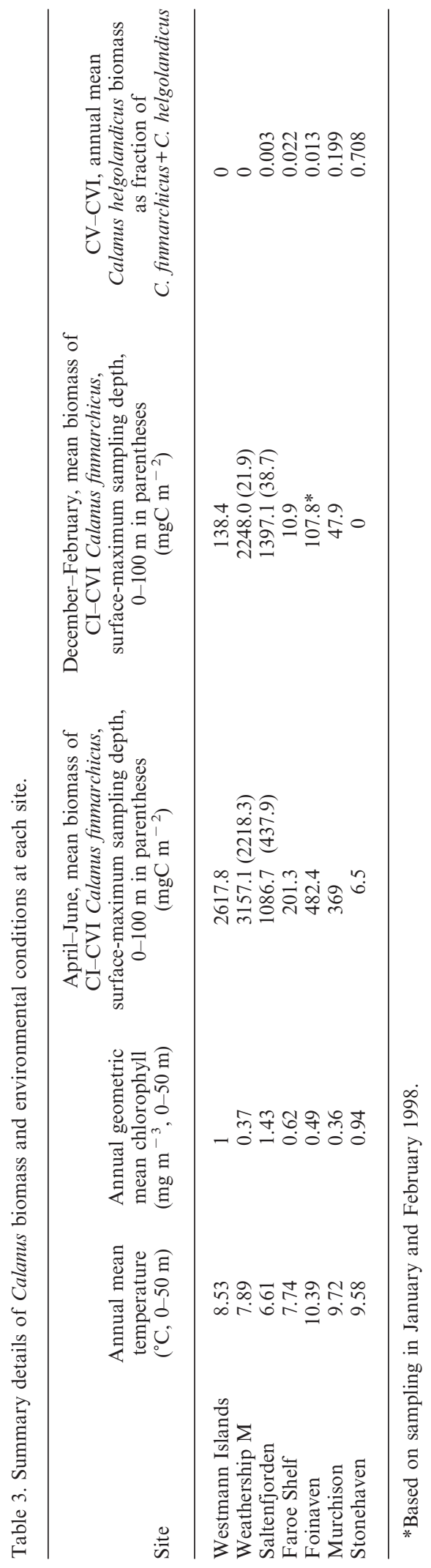


The Murchison site, on the northern slope of the North Sea, and the Weathership M site were also affected by this inflow, but the sites at the Westmann Islands were affected by Atlantic Water flowing onto the south Icelandic Shelf. The Faroe Shelf and Saltenfjorden sites experienced the coldest mean temperatures, the former being located within the tidal circulation around the Faroe Islands, and the latter receiving quantities of cold snow-melt water from land run-off. In general, the coastal sites showed the largest amplitude of seasonal variation in temperature, and the offshore sites the smallest (Fig. 1). Annual mean chlorophyll concentration was in general lowest at the most offshore sites and highest at the coastal sites (Table 3). There was strong coherence in the timing of the spring phytoplankton bloom across the offshore and open shelf sites (Westmann Islands, Foinaven, Weathership $\mathrm{M}$ and Murchison), but a different seasonal pattern was observed at the inshore sites (Saltenfjorden and Stonehaven) and at the Faroe Shelf site (Fig. 2).

\section{Calanus spp. biomass and stage abundances}

At the northern edge of the study area, off the Westmann Islands and at Weathership M, Calanus finmarchicus and other Calanus species were the dominant copepods in the $200-\mu \mathrm{m}$ mesh plankton catch. During spring and early summer (April-June) at those sites, the mean biomass of $C$. finmarchicus in the upper $100 \mathrm{~m}$ exceeded $2 \mathrm{gC} \mathrm{m}^{-3}$ (Fig. 3, Table 3). However, off Stonehaven, at the southern edge of the study, Calanus sp. accounted for only $2 \%$ of all copepods averaged over the year, with a maximum contribution of $18 \%$. Of the Calanus spp. present at Stonehaven, the majority $(70 \%)$ were $C$. helgolandicus, which was especially abundant in autumn and early winter. The spring/summer mean biomass of $C$. finmarchicus off Stonehaven was $<0.01 \mathrm{gC} \mathrm{m}^{-3}$ (Fig. 3, Table 3). The proportion of $C$. helgolandicus was highest in the North Sea, and low $(<3 \%)$ elsewhere (Table 3$)$. C. hyperboreus was caught at the Foinaven and Weathership M sites, and $C$. glacialis at Weathership $\mathrm{M}$, but data on those species are not considered here.

At Weathership M and Saltenfjorden, where depthresolved sampling was carried out, the biomass of $C$. finmarchicus copepodites was concentrated in the upper $100 \mathrm{~m}$ in spring and early summer (April-June), and in the deeper layers $(>100 \mathrm{~m})$ during winter (DecemberFebruary; Fig. 3, Table 3). The winter biomass at these sites, integrated to the maximum sampling depth, was comparable to that present during spring and summer (Table 3). However, the winter population consisted mainly of CV stages, whereas the spring/summer population contained a high proportion of juvenile copepodite stages (CI-CIII; Figs 4, 5). In contrast, the depthintegrated winter biomass at each of the other sites was small $(0-20 \%)$ in comparison to that present during spring and summer (Fig. 3, Table 3), and there was no evidence of accumulating abundances of $\mathrm{CV}$ in winter (Figs 4-7). On the basis of these results, it is concluded that retention or accumulation of overwinter resting stages of $C$. finmarchicus at the end of the productive summer season occurred only at Weathership $M$ and Saltenfjorden. At the other sites, summer production was presumably either exported or consumed by predators.

\section{Forecast model}

The fitted CI-CV mortality rates for each site from the forecast model are given in Table 4; they vary by a factor of 10 between extremes. Qualitatively good agreement was obtained between the forecast model and observations of CIV and CV at the open shelf sites (Westmann Islands, Faroe Shelf, Foinaven, and Murchison; Fig. 8). The pattern of progression, from domination by CIV in early summer to domination by $\mathrm{CV}$ in autumn and winter, was successfully reproduced. However, the model systematically failed to reproduce the observed abundances of CVI copepodites in spring (fortnights 5-11). In other words, such abundances cannot be explained by internal dynamics from the incidences of CI-CIII. The conclusion is that those sites were sustained by spring invasion of CVI from remote overwintering abundances not represented in the samples. The forecast propagation of stage abundance at Foinaven suggested a single generation originating from a short burst of egg production in spring, but at the other shelf sites the pattern appeared to be one of prolonged production through spring and summer. Also at Foinaven, the observations suggested a secondary peak in CV and CVI abundance during fortnights 17 and 18 that cannot be explained by earlier abundances of CI-CIII. Presumably, these also were immigrants to the sampling site, possibly from Atlantic Water to the southwest.

A different pattern was observed at the open ocean Weathership M site (Fig. 9). Here, the forecast model predicted low abundance of CVI during fortnights 3-9, arising from moulting of overwintered CV. The observed data on CVI and CV in the upper $1600 \mathrm{~m}$ through the year were variable, but it was clear that, in contrast to the shelf sites, high abundances of mainly CV remained at the end of the year. These were located at depth in cold waters $\left(<1^{\circ} \mathrm{C}\right)$. By assuming a temperature of $0.5^{\circ} \mathrm{C}$ for diapause stages, the model was successful in predicting the overall pattern of stage abundance throughout the year. The results indicate that the population sampled at Weathership $M$ was relatively selfcontained and self-sustaining compared to those at the shelf sites. The forecast abundances of CIV suggested two discrete generations at this site, although the evi- 

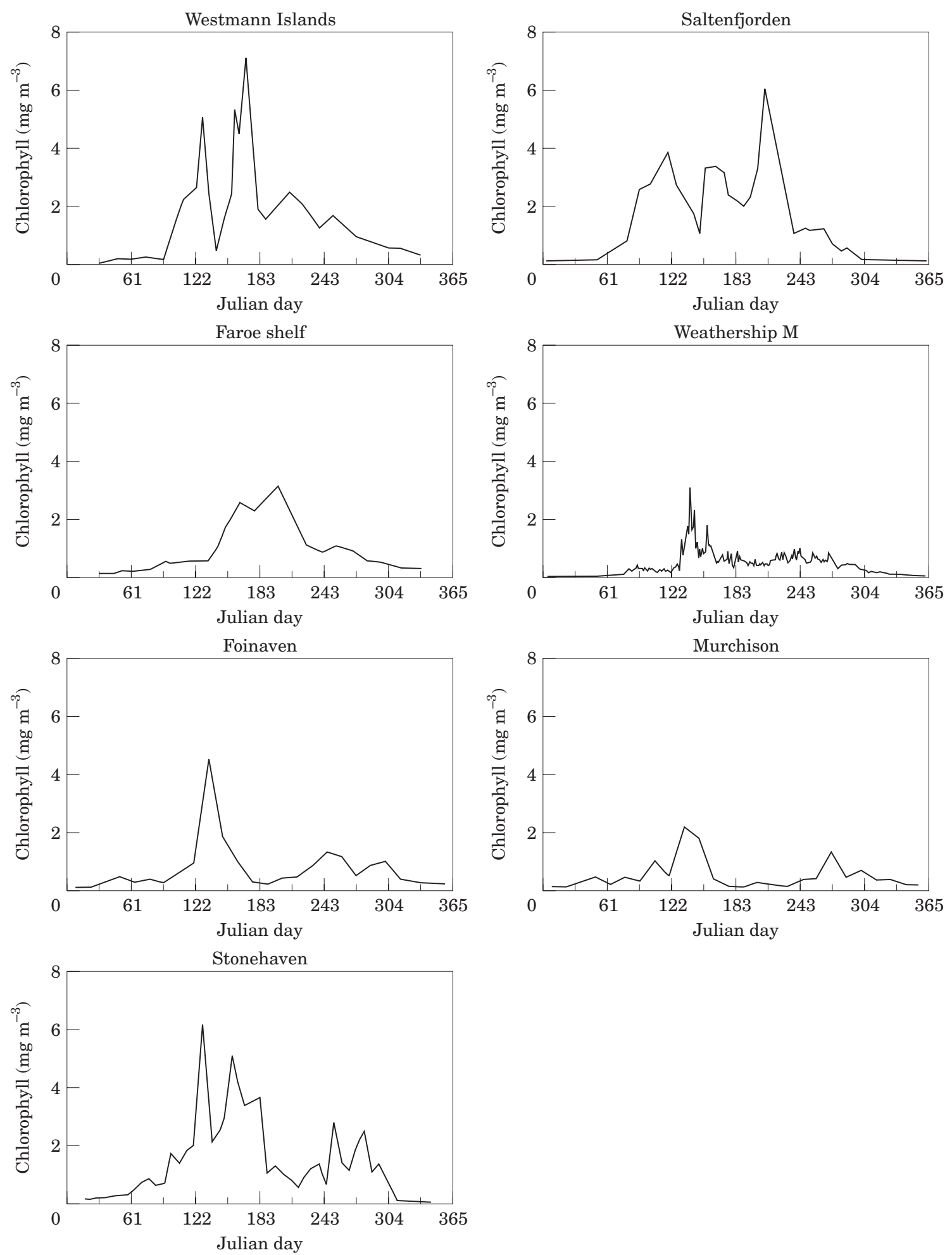

Figure 2. Seasonal cycles of chlorophyll concentration in the upper $50 \mathrm{~m}$ of the water column at each of the sampling sites. 

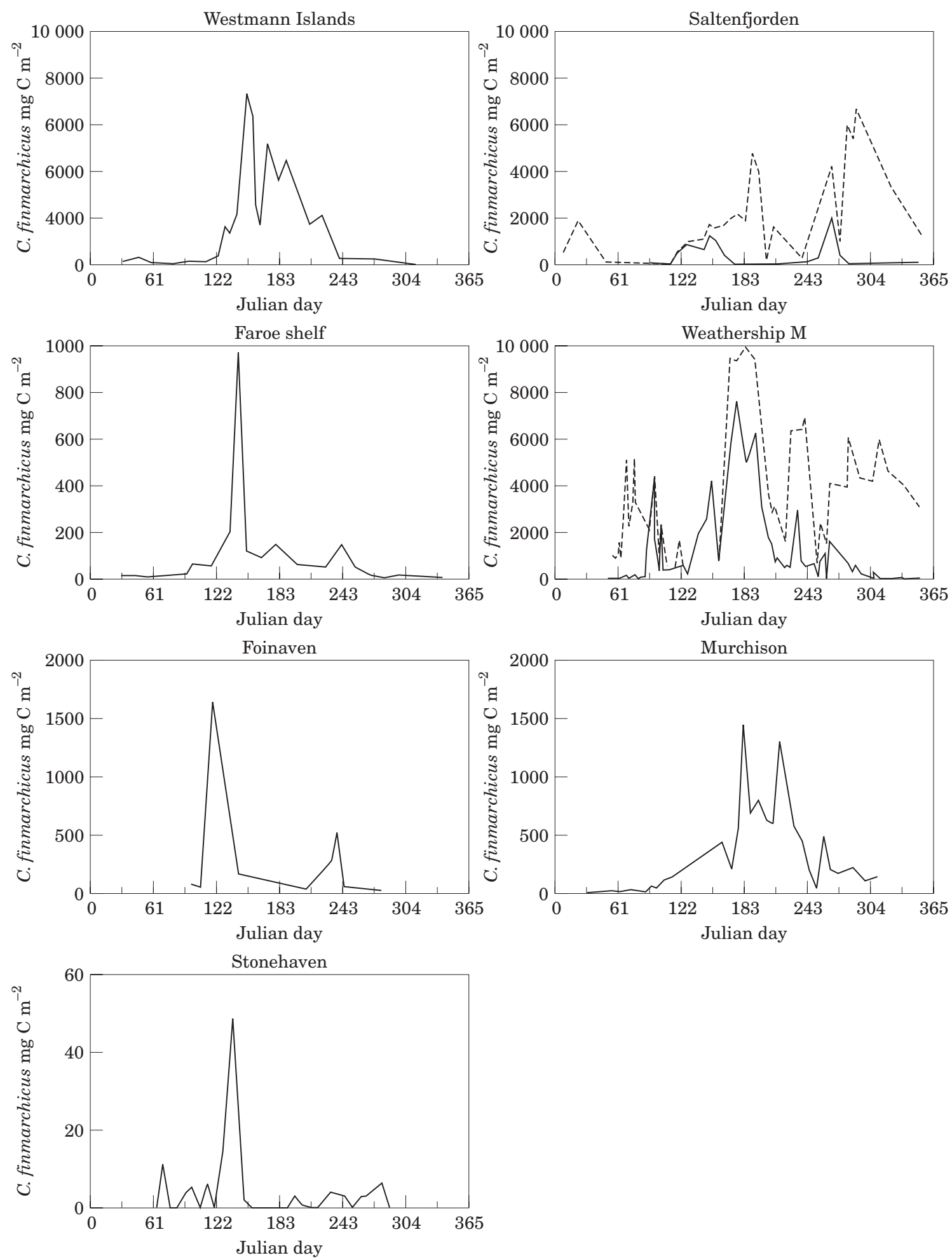

Figure 3. Seasonal cycles of $C$. finmarchicus copepodite biomass at each of the sampling sites. Solid lines indicate biomass in the total water column, except at Weathership $M$ and Saltenfjorden, where they refer to the upper $100 \mathrm{~m}$. Dashed lines indicate biomass in the upper $1600 \mathrm{~m}$ at Weathership M and in the upper $370 \mathrm{~m}$ (total water column) at Saltenfjorden. 

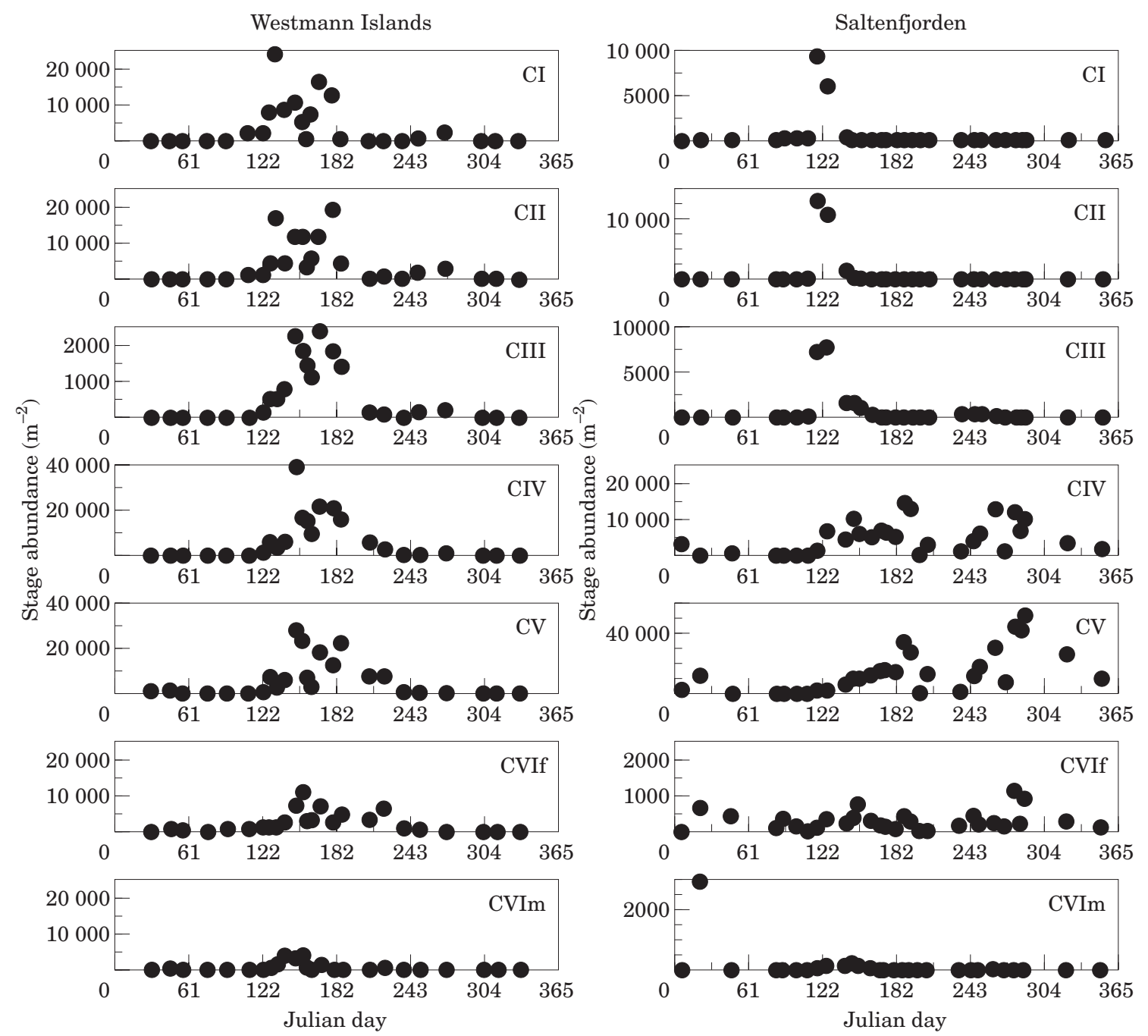

Figure 4. Measured abundances (surface to maximum sampling depth) of C. finmarchicus copepodite stages during 1997 at the Westmann Islands and Saltenfjorden.

dence was less clear from the observations. The second generation, which appeared in the model results as CIV between fortnights 17 and 21, was around an order of magnitude less abundant than the first.

The forecast model met with mixed success in explaining the population dynamics at the inshore sites (Saltenfjorden and Stonehaven; Fig. 9). At Saltenfjorden, it was clear that the abundances of CV in winter were far higher than could be explained by the incidence of CI-CIII in summer, suggesting that the site was accumulating overwintering copepodites from a wide area. To represent this crudely in the forecast model, the mortality rate of $\mathrm{CI}-\mathrm{CV}\left(\mathrm{z}_{\mathrm{c}}\right)$ was inverted to become an accumulation rate. With this modification, the model produced a qualitatively respectable account of the observations and suggested the occurrence of two dis- crete generations and a persistent overwintering stock of mainly CV. There were also two generations at Stonehaven, but the model failed to reproduce their relative magnitudes. This must have been either because of seasonal variability in mortality characteristics, or because the two generations were not internally connected and reflected production advected onto the site from elsewhere. Other factors point to the latter interpretation.

\section{Nowcast and hindcast models}

Comparison of $\mathrm{Q}_{10}$ and parabolic temperature response versions of the nowcast model, with the observed rates of egg production at Weathership M during MarchMay 1997 (Fig. 10) indicated that neither completely 
Faroe shelf
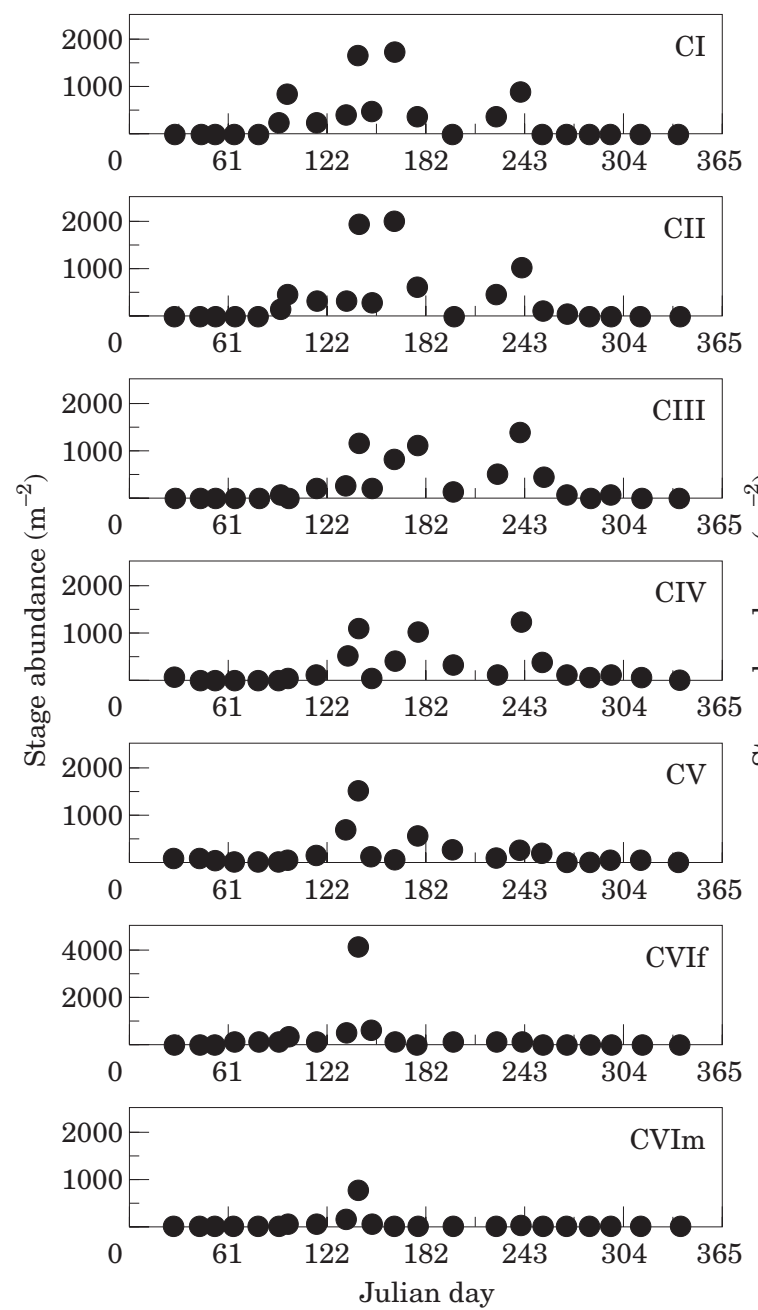

Weathership M
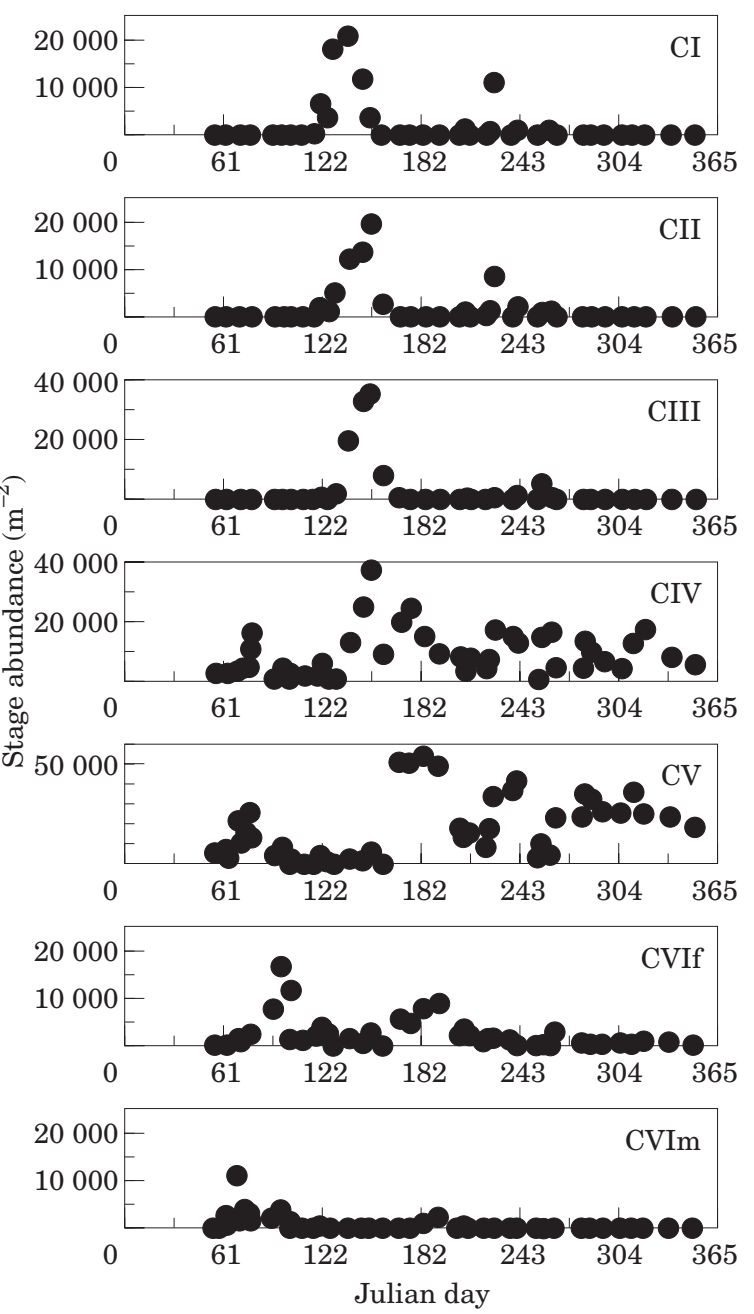

Figure 5. Measured abundances (surface to maximum sampling depth) of C. finmarchicus copepodite stages during 1997 at the Faroe Shelf and Weathership M.

explained the near cessation of egg production following the algal bloom in mid-May. However, the parabolic response model was qualitatively superior in that it correctly predicted declining egg production following peak chlorophyll concentration, whereas the $\mathrm{Q}_{10}$ model predicted the maintenance of rates $>20$ eggs female $^{-1}$ $\mathrm{d}^{-1}$.

Results from the open shelf sites indicated moderate agreement between the hindcast and nowcast models, with approximately a factor of 3 variation in fitted rates of mortality between sites (Table 5). As with the forecast model, the overall conclusion was that an intense burst of spawning occurred at Foinaven in April/May, whereas prolonged spawning occurred throughout spring and early summer at the Westmann Islands, over the Faroe Shelf and at Murchison (Fig. 11). At all open shelf sites, the nowcast egg abundance appeared to lag the hindcast abundance by around one month. This suggests inappropriate parameterization of the hindcast model leading to excessive stage durations, or enhanced survival of the early temporal components of the annual egg production, or that the sampled CI-CIII originated from different geographical areas where seasonal profiles of egg production differed significantly from those at the sampling sites.

In contrast, at Weathership $\mathrm{M}$ there was a large discrepancy between the nowcast and hindcast model results (Fig. 11). The pattern of incidence of CI-CIII implied the production of two discrete generations with peak production during fortnights 9 and 16, the first more abundant than the second, and with very low production during midsummer (fortnights 11-14). The 
Foinaven
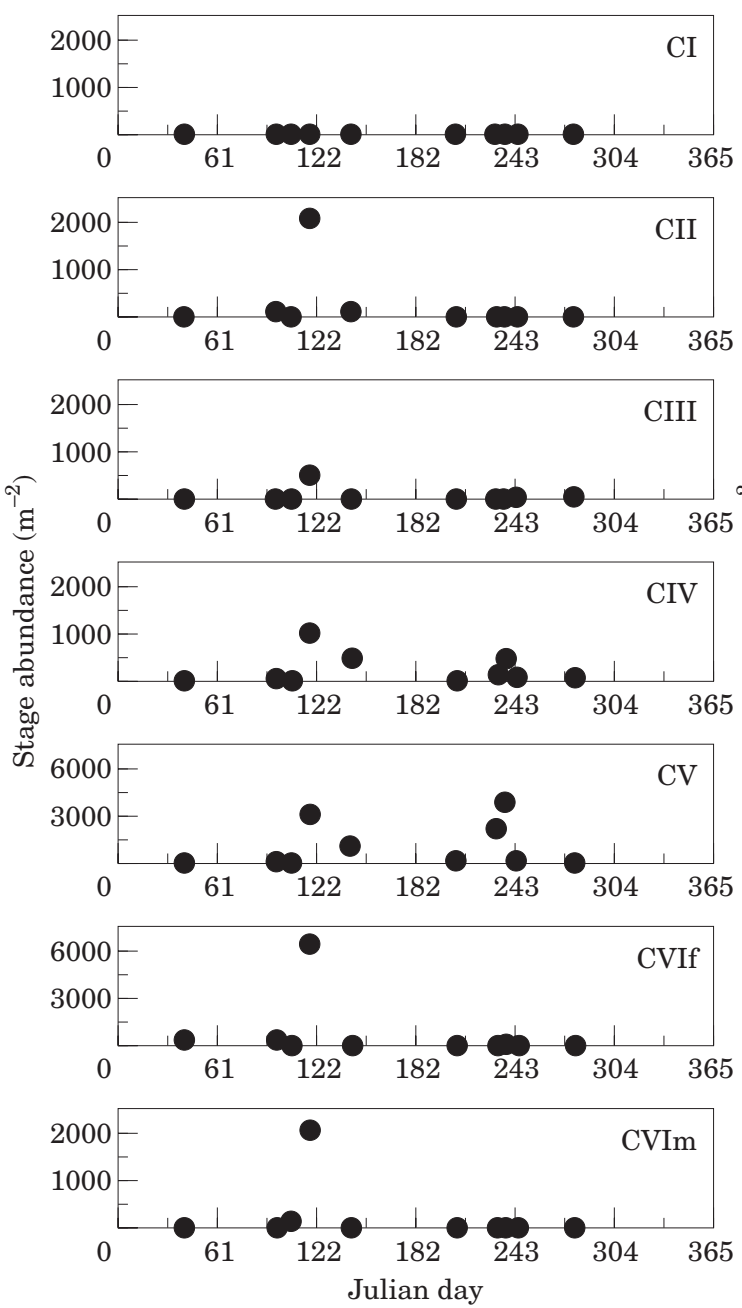

Murchison
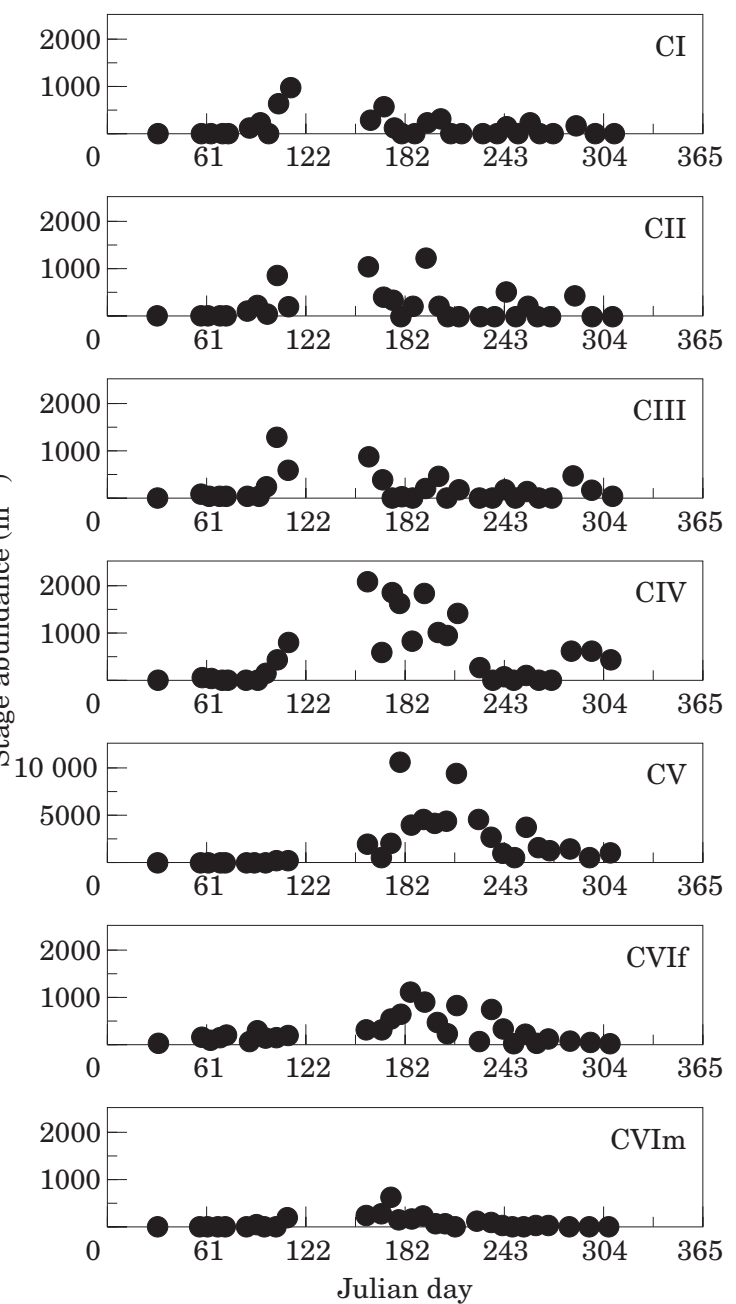

Figure 6. Measured abundances (surface to maximum sampling depth) of $C$. finmarchicus copepodite stages during 1997 at the Foinaven and Murchison offshore installations.

first peak (week 9) coincided with the onset of the spring phytoplankton bloom. In fact, females were abundant through summer and, according to the nowcast model, they should have been producing significant numbers of eggs, especially during fortnights $12-15$.

As at Weathership M, there was a large discrepancy between the hindcast and nowcast model results at Saltenfjorden (Fig. 11). The hindcast model indicated two discrete generations, the second much less abundant than the first, with peak productions at fortnight 7 , coinciding with the spring phytoplankton bloom, and fortnight 17 . The nowcast model also indicated peaks in egg abundance of similar relative magnitudes at the same times, but also a large peak in egg abundance around fortnights 10-12. At Stonehaven, both the hindcast and nowcast models were in agreement that there were two extended periods of production during fort- nights $5-10$ and $14-19$, but the relative magnitudes were different from the two models.

\section{Discussion}

\section{Overall distribution}

The generic pattern of Calanus finmarchicus seasonal abundance in the Northeast Atlantic identified by Planque et al. (1997) differed in detail from that observed at almost every site in the comparative programme. The spring invasion of shelf and surface waters by overwintered CVI resulted in peaks of population biomass at the sites fringing the Faroe-Shetland Channel, and those with indigenous overwintering stocks, namely Weathership $\mathrm{M}$ and Saltenfjorden. There, some of the highest values of water-column- 


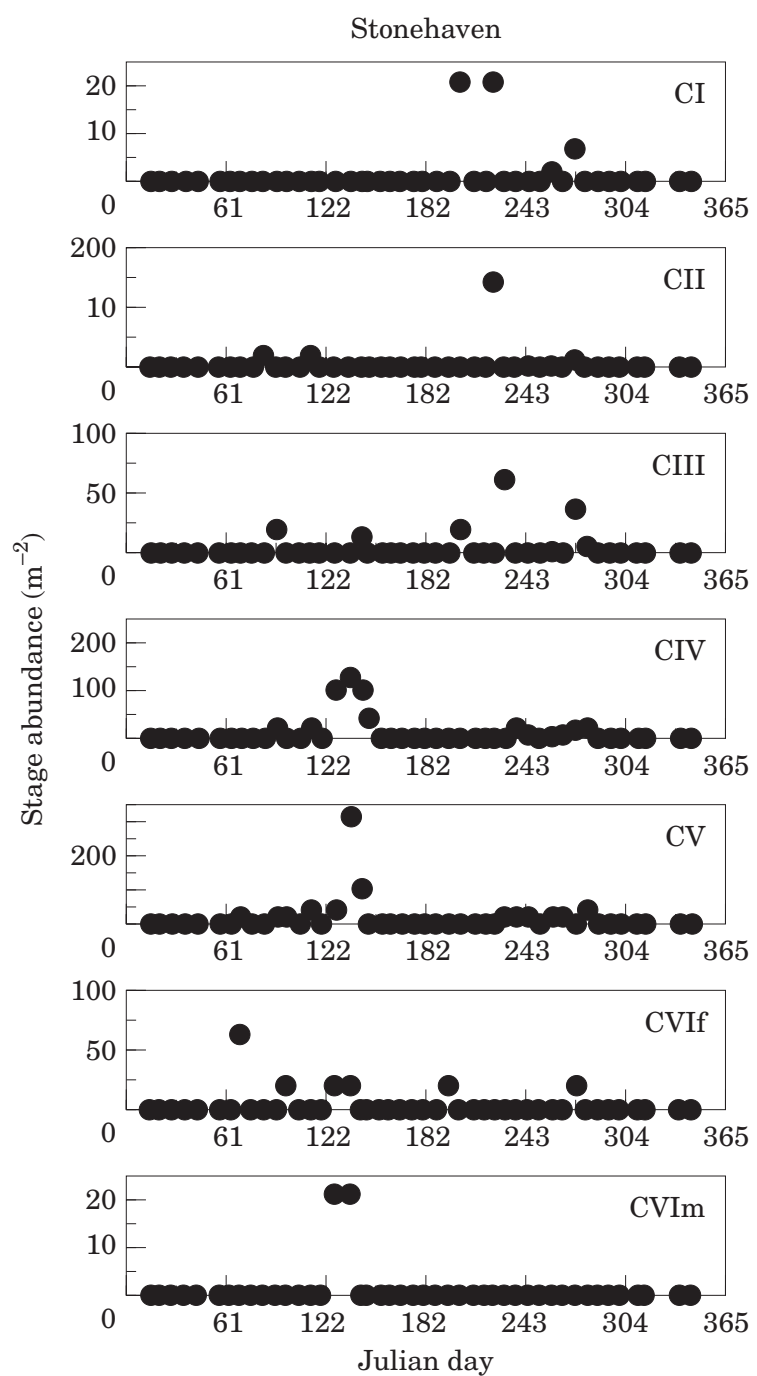

Figure 7. Measured abundances (surface to maximum sampling depth) of C. finmarchicus copepodite stages during 1997 at Stonehaven.

Table 4. Site-specific parameter values used in the forecast model.

\begin{tabular}{lcc}
\hline & $\begin{array}{c}\text { "Best fit" CI-CV } \\
\text { mortality rate } \mathrm{z}_{\mathrm{c}} \\
\left(\mathrm{d}^{-1}\right)\end{array}$ & $\begin{array}{c}\text { Temperature for } \\
\text { diapause stages }\end{array}$ \\
\hline $\begin{array}{l}\text { Westmann } \\
\quad \text { Islands }\end{array}$ & 0.006 & As for surface population \\
$\begin{array}{l}\text { Weathership M } \\
\text { Saltenfjorden }\end{array}$ & 0.004 & $0.5^{\circ} \mathrm{C}$ \\
$\begin{array}{l}\text { Faroe Shelf } \\
\text { Foinaven } \\
\text { Murchison }\end{array}$ & 0.004 & $4^{\circ} \mathrm{C}$ \\
Stonehaven & 0.002 & $\begin{array}{l}\text { As for surface population } \\
\text { As for surface population }\end{array}$ \\
\hline
\end{tabular}

integrated biomass were obtained in late summer and early winter owing to the accumulation of overwintering stock.

There was a clear latitudinal trend in both the biomass of $C$. finmarchicus and its dominance over the sibling species $C$. helgolandicus. However, there was no simple relationship between $C$. finmarchicus biomass and chlorophyll or temperature, either on an annual mean basis, or within the annual cycle. This raises the question of exactly what factors determine latitudinal range of a species. The models applied in this study indicate that coupling between the life cycle and seasonal cycles of food and temperature, together with the proximity of overwintering habitats, largely determine the demography and productivity of $C$. finmarchicus at a given site.

\section{Forecast model}

The central feature of the forecast model was a simple representation of diapause entry and duration, elaborated slightly from that of Hind et al. (2000). Despite the vital importance of diapause in the life cycle of $C$. finmarchicus, understanding the regulating processes remains elusive. Hirche (1996) reviewed the information on diapause and identified a number of physiologically distinct phases, but was unable to identify the cues for entry or emergence. Hind et al. (2000) summarized the main hypotheses on factors governing diapause, and showed by application of simple models that environmental cueing of emergence date is not a prerequisite for synchronization of the life cycle to seasonal cycles in the environment. Plausible seasonal patterns of reproduction can be obtained simply by assuming suppression of normal development rates while in diapause. Similarly, the factors determining whether an individual copepodite accumulates lipid in readiness for overwintering, or proceeds to develop into a mature adult, remain obscure.

Most previous attempts at modelling the life cycle have "hardwired" the fraction of each generation entering diapause at a given developmental stage. Following from Hind et al. (2000), we invoked diapause entry by means of threshold food level encountered during a developmental window. As each cohort in the model has a unique phase relationship to the seasonal cycles of temperature and chlorophyll, the proportion entering diapause in a given period is an entirely dynamic property of the model. This representation of diapause entry rules by no means indicates that we believe food concentration per se to be the key factor, but it is logical that a copepodite should respond to food levels that may not support gonad development and maturation by initiating overwintering. Undoubtably, the process is considerably more complex than this. 

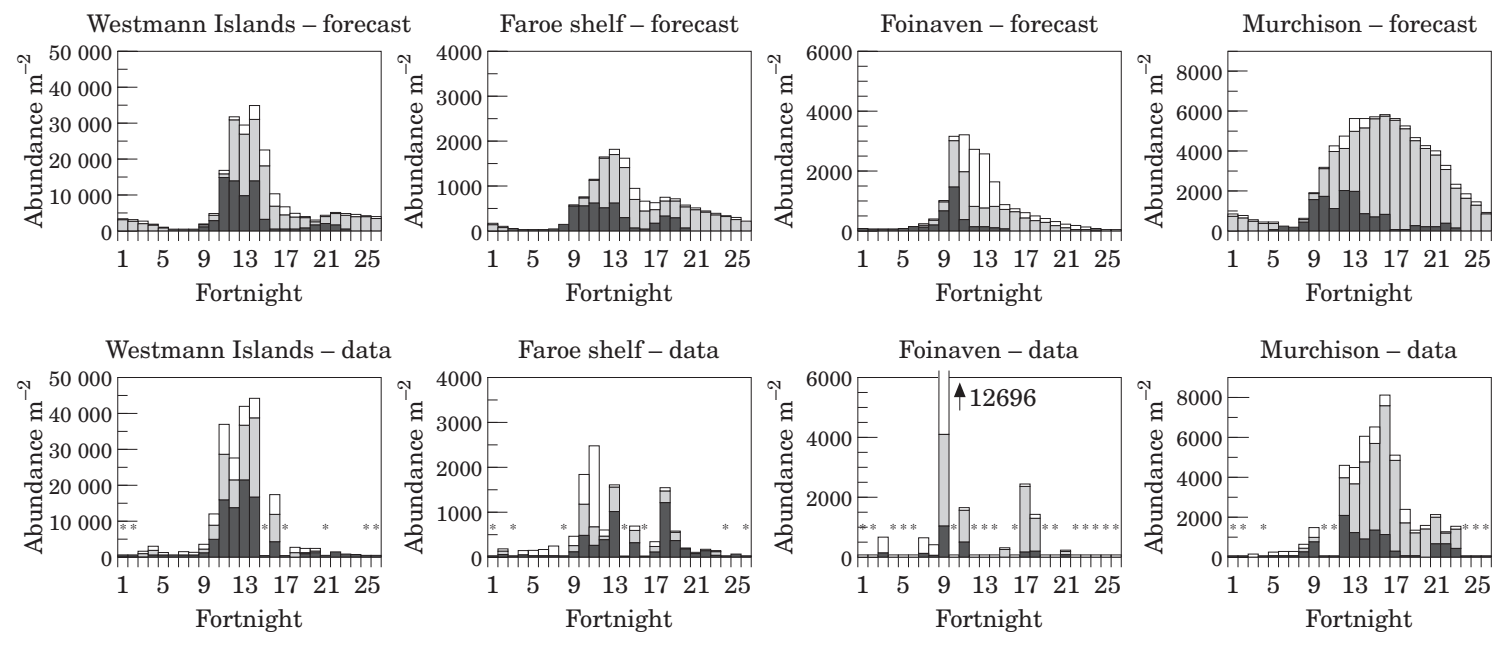

Figure 8. Comparison of fortnightly averaged forecast model results and observed abundances of CIV, CV, and CVI at the Westmann Islands, over the Faroe Shelf, at Foinaven and at Murchison. Asterisks in the observation series indicate no sampling in a given fortnight period.
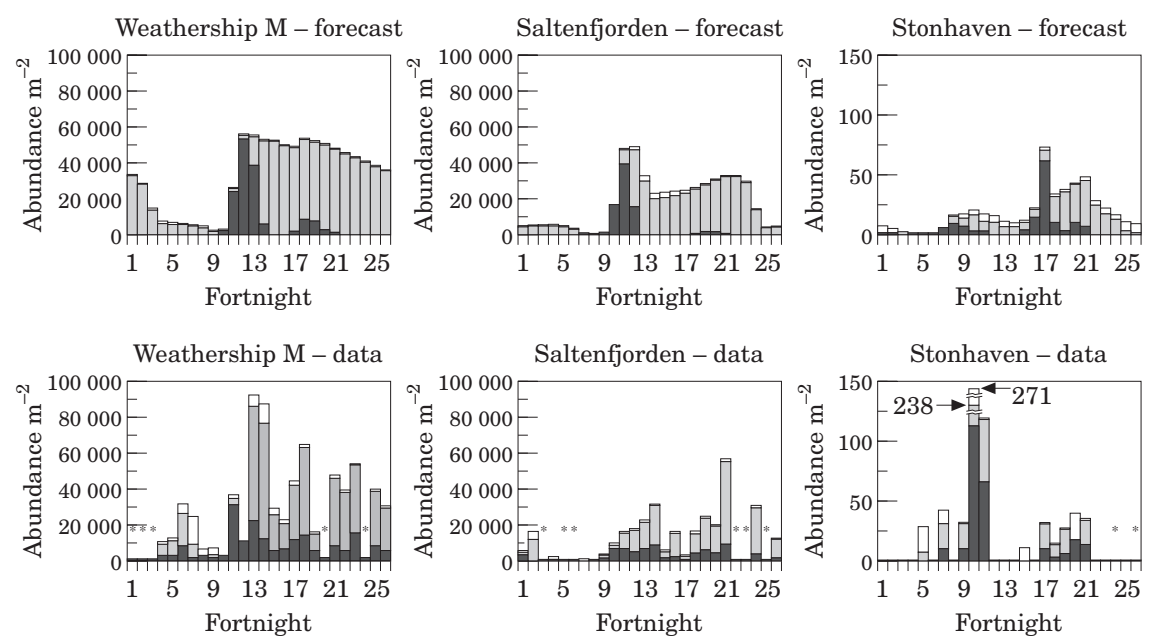

Figure 9. Comparison of fortnightly averaged forecast model results and observed abundances of CIV, CV, and CVI at Weathership M, Saltenfjorden, and Stonehaven. Asterisks in the observation series indicate no sampling in a given fortnight period.

Despite the simplistic portrayal of diapause processes, the forecast model was in general successful in predicting the demography of stages CIV-CVI at the range of sites with only a minimum of site-specific parameter fitting. The range of mortality rates required to obtain semiquantitative fits to the observations was comparatively small, with the exception of Saltenfjorden, where the demography was clearly dislocated by advective processes. From this we can conclude that the model was an adequate representation of the processes given the resolution of the observations.

\section{Hindcast and nowcast models}

There was a clear failure of the hindcast and nowcast models to agree in detail at most sites, especially at Weathership $M$ and Saltenfjorden. It is difficult to interpret these discrepancies, which may be due to a number of different causes. At open shelf sites the lag between hindcast and nowcast model results may be suggestive of advective influence, the CI-CIII having been spawned at distant locations where the seasonal profile of population egg production was different from 


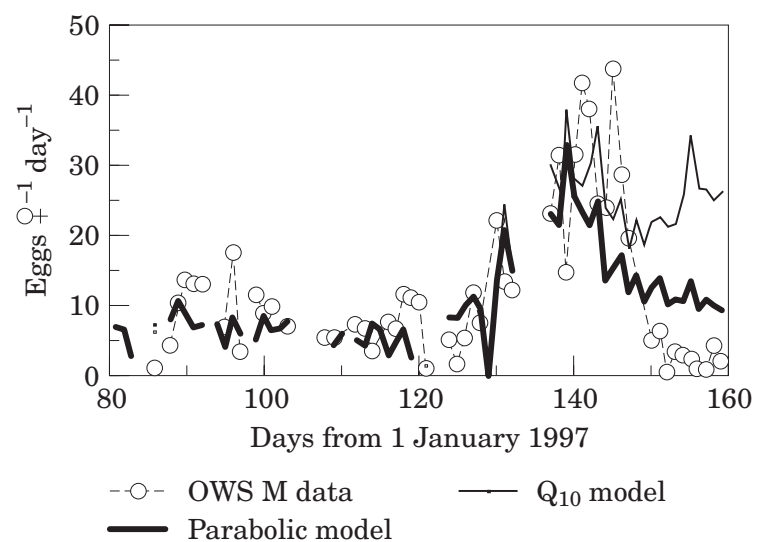

Figure 10. Time series of observed rate of egg production (eggs female ${ }^{-1} \mathrm{~d}^{-1}$ ) at Weathership $M$ from Niehoff et al. (1998), together with nowcast model results incorporating the $\mathrm{Q}_{10}$ temperature response and parabolic temperature response.

Table 5. Site-specific parameter values used in the hindcast model $\left(\mathrm{z}_{\mathrm{c}}=0.005 \mathrm{~d}^{-1} ;-0.005 \mathrm{~d}^{-1}\right.$ at Saltenfjorden).

\begin{tabular}{lc}
\hline Site & $\begin{array}{c}\text { "Best fit" egg }- \text { NVI } \\
\text { mortality rate } \mathrm{z}_{\mathrm{j}}\left(\mathrm{d}^{-1}\right)\end{array}$ \\
\hline Westmann Islands & 0.13 \\
Weathership M & 0.04 \\
Saltenfjorden & 0.01 \\
Faroe Shelf & 0.27 \\
Foinaven & 0.275 \\
Murchison & 0.08 \\
Stonehaven & 0.2 \\
\hline
\end{tabular}

that at the sampling sites. However, this is unlikely to be the case at Weathership M, which by all other measures appears to be relatively self-contained. We must therefore conclude that the representation of some aspects of biology in the models is flawed.

The processes involved in the hindcast model govern only the rates of development and mortality. Although development rate is unlikely to be solely a function of temperature, the likely variability attributable to other factors such as food does not seem sufficient to account for the discrepancies between the models. However, it is conceivable that variation in the mortality rates of eggs and nauplii, which were assumed to be constant in the hindcast model, could have generated the discrepancies. Such variations could result in the survivors to stage CI being drawn selectively from discrete temporal components of annual egg production. This interpretation would be consistent with data on egg and nauplius abundance collected at Weathership M (Hirche et al., 1999), which indicate that, although adult $C$. finmarchicus produced eggs even at low concentrations of food prior to the spring phytoplankton bloom, the survivors to late nauplii and CI stages arose mainly from eggs produced during the onset of the bloom.

Turning to the nowcast model, the parabolic temperature response function is a crude representation of both true temperature dependency and a documented, but poorly defined, food quality, seasonal or generationbased component to the potential egg production of females. The midsummer temperature in the upper $100 \mathrm{~m}$ at Weathership $\mathrm{M}$ is less than $10^{\circ} \mathrm{C}$, too low to force cessation of egg production by the parabolic response function, but at the warmer open shelf sites, where the two models are in better agreement, the parabolic response does force a reduction in production. We conclude that there is a major gap in our understanding of seasonal variations in rate of egg production. Lack of knowledge of the extent of carnivorous feeding may be partly responsible, but this does not help explain the gross discrepancies in rates of egg production during and after the spring bloom at, for example, Weathership M. We might expect carnivorous feeding to become more important after the spring phytoplankton bloom and thereby to increase egg production relative to chlorophyll in the post-bloom period; in fact, the reverse is the case. Simple relationships with food and temperature seem not to be applicable over the whole spring and summer productive season, and some endogenous factors may be involved. The simple temperaturedependent parabolic response form used here, though successful in mimicking this effect at some sites, is not a satisfactory basis for modelling, and cannot be applied in a standard form across all locations without the undesirable feature of site-specific parameterization.

\section{Regional variations in demographic pattern}

As well as testing hypotheses regarding life-cycle processes, the sampling programme was intended to investigate regional variations in demography. The main conclusion in this regard is that proximity to overwintering sites is a key factor in determining whether discrete generations are produced at a site. Two discrete generations were observed at both Weathership $M$ and Saltenfjorden, where high concentrations of overwintering stages were sampled in the subsurface layers. The Foinaven site was close to, but not actually within, the overwintering site in the Faroe-Shetland Channel (Heath and Jónasdóttir, 1999), and a single discrete generation was observed there following the intense spring invasion of overwintering stock onto the continental slope region.

There was no significant overwintering at the open shelf sites (Westmann Islands, Faroe Shelf, and Murchison). There, production of eggs was continuous during spring and summer, with no clear temporal separation of generations. The reasons may be related to remoteness from overwintering aggregations leading to temporal "smearing" of the invasion of females in spring 

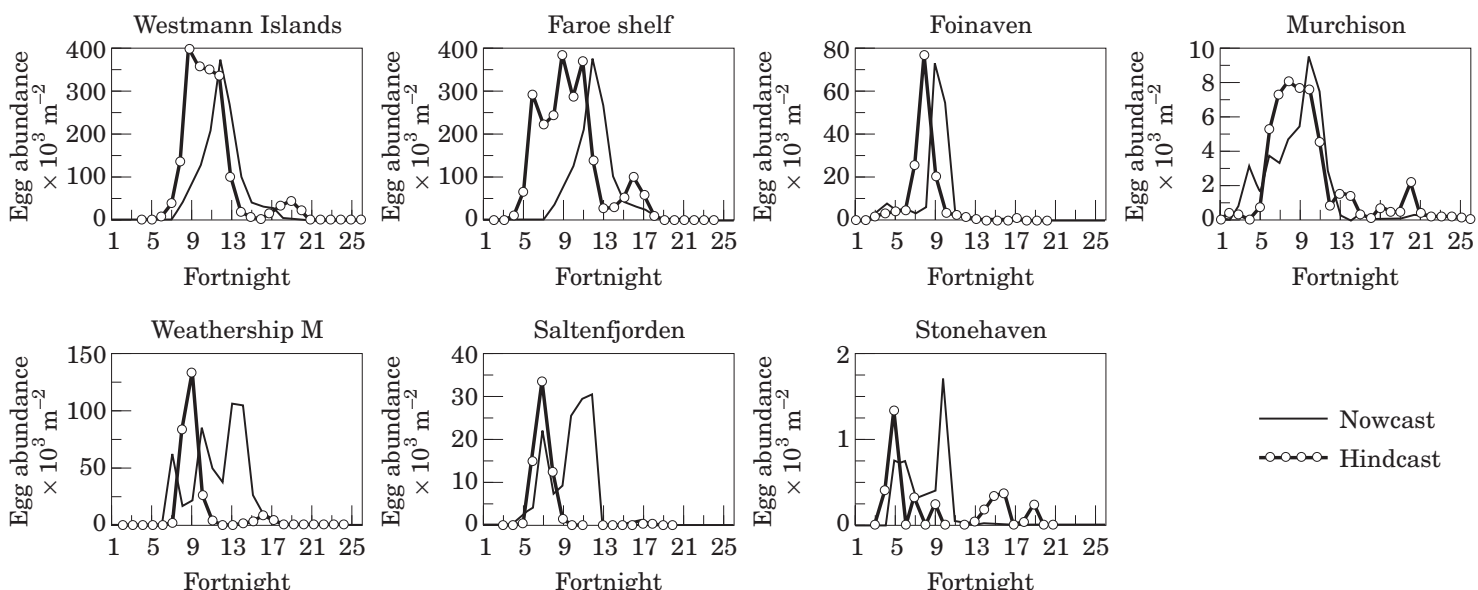

Figure 11. Comparisons of fortnightly averaged hindcast and nowcast model estimates of egg abundance at the seven sampling sites.

as a result of advective and diffusive processes, and/or to the seasonal pattern of primary production in shelf waters. Two, or possibly three, generations were achieved at each of the open shelf sites. The lack of overwintering at the shelf sites must largely be due to hydrodynamic factors preventing physical retention, but it can also be linked to the temperature regimes. The forecast model predicted that copepodites attempting to overwinter in warm shelf water should emerge too early to contribute to the first generation of the following year, so suffering high mortality. The implication is that access to low temperature habitat is an advantageous condition for colonization of a region by $C$. finmarchicus.

The inshore sites (Saltenfjorden and Stonehaven) were the most affected by advection. Saltenfjorden was clearly an accumulating site, collecting overwintering stages from a much wider area than the immediate vicinity of the sampling site. Stonehaven was at the southerly limit of the latitudinal range of C. finmarchicus, and though there were two clear periods of production, one in spring and one in autumn, it was difficult to ascertain a demographic connection rather than attribute it to advection of females into the area, because the species was almost absent through summer. Nevertheless, the pattern of production in 1997 was repeated in 1998 and 1999 (data not shown here), suggesting that, even if the two generations are not linked at the site, they do reflect persistent demographic processes offshore.

\section{Acknowledgements}

Many personnel at all our Institutes provided essential support for this coordinated programme of sampling, both in the laboratory and in the field. These include
Robert Head (PML), Signe Johannessen (IMR), Ulrike Klenke (AWI), Morten Krogstad (NOC), Hildur Petursdóttir (MRI), Susan Robinson (MLA), Ian Watson (coxwain of the RV "Shuna"), Ian Napier (North Atlantic Fisheries College, Shetland), and A. Timonin and T. Semenova from the Shirshov Institute of Oceanology, Russian Academy of Science. We are also grateful to the research vessel crews, to Oryx UK Ltd and their safety officers on the Murchison Platform for support with sampling in the North Sea, to Golar Nor Ltd, British Petroleum and the crews of the MV "Grampian Frontier" for support with sampling at the Foinaven oil-field west of the Shetland Isles, and the crew of MV "Polarfront" for support with sampling in the Norwegian Sea. The programme was partly supported by European Union TASC project (MAS3CT95-0039).

\section{References}

Conover, R. J. 1988. Comparative life histories in the genera Calanus and Neocalanus in high latitudes of the northern hemisphere. Hydrobiologia, 167/168: 127-142.

Falkenhaug, T., Tande, K. S., and Timonin, A. 1997. Spatiotemporal patterns in the copepod community in Malangen, northern Norway. Journal of Plankton Research, 19: 449464.

Gislason, A., and Astthorsson, O. S. 1996. Seasonal development of Calanus finmarchicus along an inshore-offshore gradient southwest of Iceland. Ophelia, 44: 71-84.

Gislason, A., and Astthorsson, O. S. 1998. Seasonal variations in biomass, abundance and composition of zooplankton in the subarctic waters north of Iceland. Polar Biology, 20: 85-94.

Hay, S. J., Kiørboe, T., and Matthews, A. 1991. Zooplankton biomass and production in the North Sea during the Autumn Circulation Experiment, October 1987 to March 1988. Continental Shelf Research, 11: 1453-1476. 
Heath, M. R , and Jónasdóttir, S. H. 1999. Distribution and abundance of overwintering Calanus finmarchicus in the Faroe-Shetland Channel. Fisheries Oceanography, 8: 40-60.

Hind, A. T., and Gurney, W. S. G. 1998. Life-cycle synchrony in a marine copepod. Archive für Hydrobiologie. Special Issue on Advances in Limnology, 52: 327-337.

Hind, A. T., Gurney, W. S. C., Heath, M. R., and Bryant, A. 2000. Overwintering strategies in Calanus finmarchicus. Marine Ecology Progress Series, 193: 95-107.

Hirche, H.-J. 1991. Distribution of dominant calanoid copepod species in the Greenland Sea during late fall. Polar Biology, 11: 351-362.

Hirche, H-J. 1996. Diapause in the marine copepod, Calanus finmarchicus - a review. Ophelia, 44: 129-143.

Hirche, H.-J., Brey, T., and Niehoff, B. 1999. A high frequency time series at Weathership M, Norwegian Sea. Population dynamics of Calanus finmarchicus. In TASC Final Report November 1999 (EU-MAS3-CT95-0039), Task 2.2, Annex 6, $18 \mathrm{pp}$.. Ed. by E. Halvorsen, and K. Tande. University of Tromsø, Norwegian College of Fishery Science. 74 pp.

Hirche, H.-J., and Kwasniewski, S. 1997. Distribution, reproduction and development of Calanus species in the northeast Atlantic in relation to environmental conditions. Journal of Marine Systems, 10: 299-317.

Hirche, H.-J., Meyer, U., and Niehoff, B. 1998. Egg production of Calanus finmarchicus: effects of temperature, food and season. Marine Biology, 127: 609-620.

Ingvarsdóttir, A. 1998. Seasonal changes in physiology and chemical composition of Calanus finmarchicus late copepodite stages. PhD thesis, University of Aberdeen. $152 \mathrm{pp}$.

Ingvarsdóttir, A., Houlihan, D. F., Heath, M. R., and Hay, S. J. 1999. Seasonal changes in respiration rates of copepodite stage V Calanus finmarchicus (Gunnerus). Fisheries Oceanography, 8(Suppl. 1): 73-83.

Irigoien, X. 1999. Vertical distribution and population dynamics of Calanus finmarchicus at station India $\left(5^{\circ} \mathrm{N}, 19^{\circ} \mathrm{W}\right)$ during the passage of the great salinity anomaly, 1971-1975. Deep-Sea Research I, 47: 1-26.

Longhurst, A., and Williams, R. 1992. Carbon flux by seasonal vertical migrant copepods is a small number. Journal of Plankton Research, 14: 1495-1509.

Marshall, S. M., and Orr, A. P. 1957. The life history of the copepod Calanus finmarchicus in different latitudes. Annales Biologiques, 33: 43-47.

Matthews, J. B. L. 1969. Continuous plankton records: the geographical and seasonal distribution of Calanus finmarchicus s.l. in the north Atlantic. Bulletin of Marine Ecology, 6: 251-273.

Nichols, J. H., and Thompson, A. B. 1991. Mesh selection of copepodite and nauplius stages of four calanoid copepod species. Journal of Plankton Research, 13: 661-171.

Niehoff, B., Klenke, U., Hirche, H.-J., Irigoien, X., Head, R., and Harris, R. 1999. A high frequency time series at Weathership M, Norwegian Sea, during the 1997 spring bloom: the reproductive biology of Calanus finmarchicus. Marine Ecology Progress Series, 176: 81-92.

Planque, B., Hays, G., Ibanez, F., and Gamble, J. C. 1997. Large-scale spatial variations in the seasonal abundance of Calanus finmarchicus. Deep-Sea Research, 44: 315-326.

Richardson, K., Jónasdóttir, S. H., Hay, S. J., and Christoffersen, A. 1999. Calanus finmarchicus egg production and food availability in the Faroe-Shetland Channel and northern North Sea: October-March. Fisheries Oceanography, 8: 153162.

Runge, J. A. 1985. Egg production rates of Calanus finmarchicus in the sea off Nova Scotia. Archiv für Hydrobiologie, 21: $33-40$.
Tande, K. S. 1982. Ecological investigations on the zooplankton community of Balsfjorden, northern Norway: generation cycles, and variations in body weight and body content of carbon and nitrogen related to overwintering and reproduction in the copepod Calanus finmarchicus (Gunnerus). Journal of Experimental Marine Biology and Ecology, 62: 129142.

Tande, K. S. 1988. Aspects of developmental and mortality rates in Calanus finmarchicus related to equiproportional development. Marine Ecology Progress Series, 44: 51-58.

\section{Appendix}

Equations governing the forecast, hindcast, and nowcast models are given below. Values of the various parameters are given in Table 6.

Driving variables:

$\mathrm{T}_{\mathrm{t}}=$ temperature at time $\mathrm{t}$

$\mathrm{C}_{\mathrm{t}}=$ chlorophyll $\left(\mathrm{mg} \mathrm{m}^{-3}\right)$ at time $\mathrm{t}$

Derived variables:

$\mathrm{c}_{\mathrm{t}}=$ Development index at time $\mathrm{t}\left(0 \# \mathrm{c}_{\mathrm{t}} \# 13\right)$

$\mathrm{s}_{\mathrm{t}}=$ Moult stage, $\mathrm{s}_{\mathrm{t}}=\operatorname{int}\left(\mathrm{c}_{\mathrm{t}}\right)\left(\mathrm{s}_{\mathrm{t}}=0\right.$, eggs; $\mathrm{s}_{\mathrm{t}}=1, \mathrm{NI} ; \mathrm{s}_{\mathrm{t}}=6$, $\left.\mathrm{NVI} ; \mathrm{s}_{\mathrm{t}}=7, \mathrm{CI} ; \mathrm{s}_{\mathrm{t}}=12, \mathrm{CVI}\right)$

$\mathrm{d}(\mathrm{s})_{\mathrm{t}}=$ development rate at time $\mathrm{t}=$ reciprocal of the stage duration

$\mathrm{F}_{\mathrm{t}}=$ food $\left(\mathrm{mg} \mathrm{m}^{-3}\right)$ at time $\mathrm{t}$

$\beta_{\mathrm{F}, \mathrm{T}}=$ egg production rate (female ${ }^{-1} \mathrm{~d}^{-1}$ ) at food concentration $F_{t}$ and temperature $T_{t}$ at time $t$

Food concentration at time $\mathrm{t}$,

$\mathrm{F}_{\mathrm{t}}=\mathrm{r} \cdot \mathrm{C}_{\mathrm{t}}$

Developmental equations:

Developmental index at time $\mathrm{t}$ (according to Hind et al., 2000),

$c_{t}=\int_{0}^{t} d(s)_{t} \cdot d t$

For $\mathrm{c}<11$,

$\mathrm{d}(\mathrm{s})_{\mathrm{t}}=\mathrm{a}_{\mathrm{s}}\left(\mathrm{T}_{\mathrm{t}}\right)^{\mathrm{b}_{\mathrm{s}}}$

For c

$\mathrm{d}(\mathrm{s})_{\mathrm{t}}=\left(\mathrm{a}_{\mathrm{s}}+\left(\mathrm{T}_{\mathrm{t}}\right) \mathrm{b}_{\mathrm{s}}\right)^{-1}$

During resting in CIV or $\mathrm{CV}\left(\mathrm{c}_{\boldsymbol{*}} \cdot \mathrm{Ec}_{\mathrm{e} 1} \# \mathrm{c}_{\mathrm{x}}\right)$,

$\mathrm{d}(\mathrm{s})_{\mathrm{t}}=\Gamma \cdot \mathrm{d}(\mathrm{s})_{\mathrm{T}=5} \cdot\left(\mathrm{Q}_{10}\right)_{\mathrm{D}} \frac{\left(\mathrm{T}_{\mathrm{t}}-5\right)}{10}$

Equations describing reproductive output:

Egg production rate at $10^{\circ} \mathrm{C}$

$\beta_{\mathrm{F}, 10}=\mathrm{p}_{1} \cdot\left(\mathrm{F}_{\mathrm{t}}-\mathrm{F}_{\mathrm{h}}\right)^{\mathrm{p}_{2}}$ 


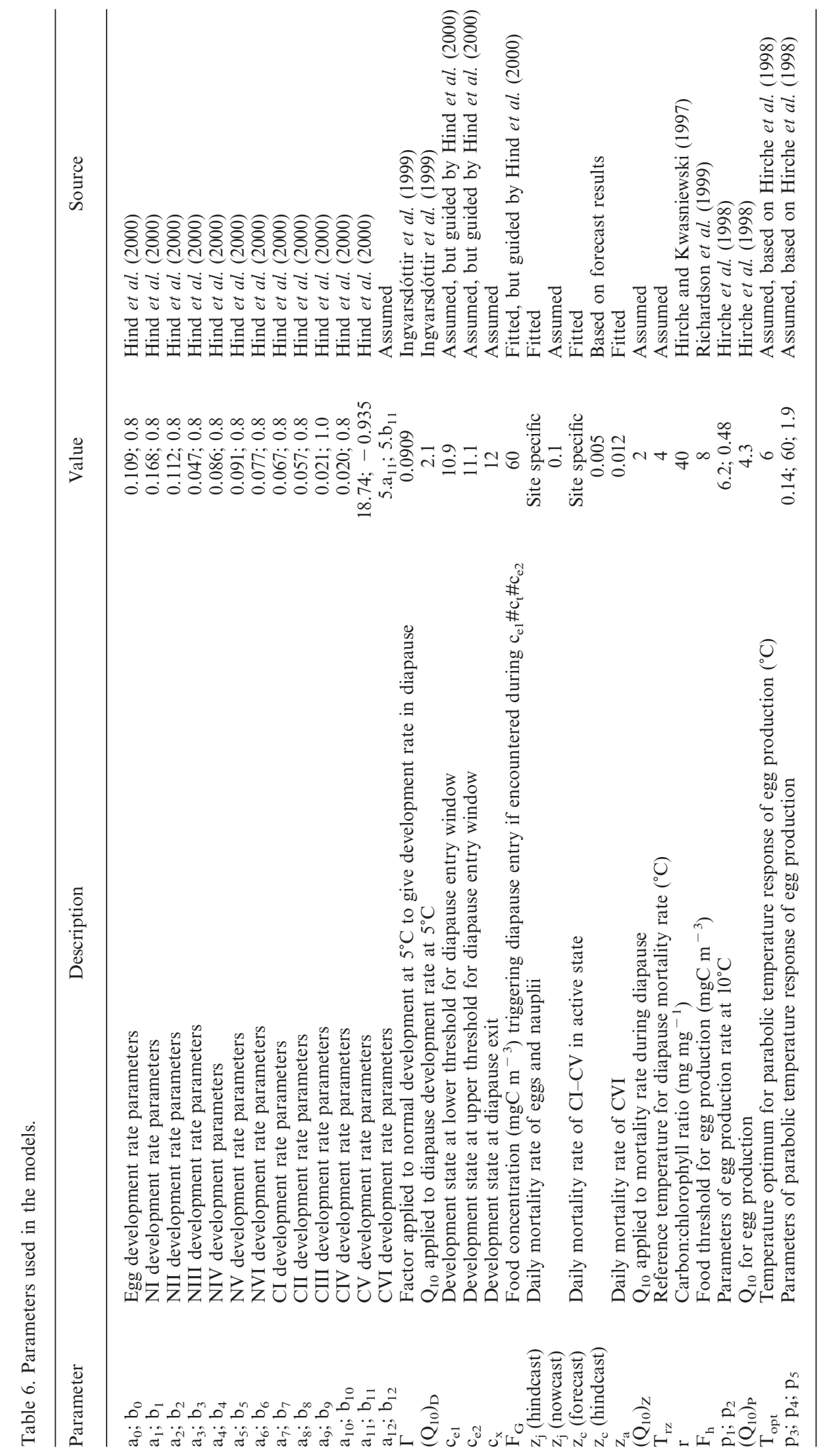


Egg production rate at temperature $T_{t}$ using a $Q_{10}$ relationship,

$\beta_{\mathrm{F}, \mathrm{T}}=\beta_{\mathrm{F}, 10} \cdot\left(\mathrm{Q}_{10}\right)_{\mathrm{P}}^{\frac{\mathrm{T}_{\mathrm{t}}-10}{10}}$
$\beta_{\mathrm{F}, \mathrm{T}}=\beta_{\mathrm{F}, 10} \cdot \mathrm{p}_{3} \cdot 10^{\frac{\mathrm{p}_{4}-\left(\left(\mathrm{T}_{\mathrm{t}}-\mathrm{T}_{\mathrm{opt}}\right) \cdot \mathrm{p}_{5}\right)^{2}}{100}}$

Egg production rate at temperature $\mathrm{T}_{\mathrm{t}}$ using a parabolic temperature relationship. 